\title{
Bioensaios em sementes de Lactuca sativa L. com extrato de folhas de Kielmeyera coriacea Mart. \& Zucc.
}

\author{
Vanessa Damasceno GONCALVES'; Maria de Fátima Barbosa COELHO'; \\ Elisangela Clarete CAMILI ${ }^{1}$ \\ vanessa-d-goncalves@hotmail.com
}

1. Universidade Federal de Mato Grosso, Avenida Fernando C. da Costa, 236719, Mato Grosso, Brasil.

Histórico do Artigo:

Recebido: 29 de fevereiro de 2016
Aceito: 26 de outubro de 2016

Publicado: xx de dezembro de 2016

\begin{abstract}
Resumo: 0 objetivo neste trabalho foi avaliar o potencial alelopático do extrato de folhas de K. coriacea, espécie nativa do Cerrado, conhecida como pau-santo, sobre a germinação e desenvolvimento de plântulas de alface. 0 extrato foi obtido com a trituração de $50 \mathrm{~g}$ de folhas em $500 \mathrm{~mL}$ de água destilada e, por diluição em água obtiveram-se as concentrações de 0, 25, 50, 75 e 100\%. 0 bioensaio foi conduzido com as cinco concentrações e quatro repetições de 50 sementes de alface. As sementes foram colocadas para germinar em caixas de plástico transparentes sobre duas folhas de papel mata-borrão umedecidas com os extratos. As caixas foram tampadas e mantidas a $20{ }^{\circ} \mathrm{C}$ e fotoperíodo de 12 horas, durante sete dias. As características avaliadas foram porcentagem de germinação e de plântulas anormais, índice de velocidade de germinação, comprimento da parte aérea e da raiz, massa fresca e seca das plântulas e, calculou-se o índice de efeito alelopático. 0 índice de velocidade de germinação, o comprimento da parte aérea e da raiz e a massa seca das plântulas diminuíram até a concentração de $75 \%$. A maior concentração do extrato ocasionou formação de 100\% de plântulas anormais. 0 extrato foliar de pau-santo não afetou a germinação das sementes que variou de 97,5 a 100\%, no entanto, o potencial alelopático foi verificado nas características de desenvolvimento das plântulas de alface.
\end{abstract}

Palavras-chave: Lactuca sativa L., Plântulas, Sementes.

\section{Bioassays in seed of Lactuca sativa L. with extract of leaves of Kielmeyera coriacea Mart. \& Zucc.}

\begin{abstract}
The objective of this study was to evaluate the allelopathic potential of the leaf extract of $K$. coriacea, native species of the Cerrado, known as lignum vitae, on the germination and development of lettuce seedlings. The extract was obtained by grinding $50 \mathrm{~g}$ of leaves in $500 \mathrm{~mL}$ of distilled water and, by dilution with water were obtained in concentrations of $0,25,50,75$ and $100 \%$. The bioassay was conducted with five levels and four replicates of 50 lettuce seeds. The seeds were germinated in transparent plastic boxes on two sheets of blotting paper moistened with the extracts. The boxes were covered and maintained at $20^{\circ} \mathrm{C}$ and photoperiod of 12 hours, for seven days. The characteristics were germination and abnormal seedlings, speed germination index, shoot length and root, fresh and dry weight of seedlings and calculated the allelopathic effect index. The speed of germination index, shoot length and root dry weight and seedling decreased to the concentration of $75 \%$. The highest concentration of the extract led to formation of $100 \%$ abnormal seedlings. The leaf extract of lignum vitae did not affect seed germination ranging from 97.5 to $100 \%$, however, the allelopathic potential was seen in developmental characteristics of lettuce seedlings.
\end{abstract}

Keywords: Lactuca sativa L., Seedlings, Seeds. 


\title{
Bioensaios en las semillas de Lactuca sativa L. con extracto de hojas de Kielmeyera coriacea Mart. \& Zucc.
}

\begin{abstract}
Resumen: El objetivo de este estudio fue evaluar el potencial alelopático del extracto de la hoja de K. coriacea, una especie nativa del Cerrado, conocido como guayacán, sobre la germinación y crecimiento de plántulas de lechuga. El extracto se obtiene por elaboración $50 \mathrm{~g}$ de hojas en $500 \mathrm{~mL}$ de agua destilada y, por dilución con agua se obtuvieron en concentraciones de 0, 25, 50, 75 y $100 \%$. El bioensayo se realizó con cinco niveles y cuatro repeticiones de 50 semillas de lechuga. Las semillas fueron germinadas en cajas de plástico transparente en dos hojas de papel secante humedecido con los extractos. Las cajas se cubrieron y se mantuvieron a $20^{\circ} \mathrm{C}$ y fotoperíodo de 12 horas, durante siete días. Las características evaluadas fueron la germinación y plántulas anormales, índice de velocidad de germinación, longitud de brotes y raíces frescas y el peso seco de las plántulas y calcularon el índice de efecto alelopático. La velocidad del índice de germinación, longitud de brote y raíz y masa seca de las plantas de semillero se redujo a la concentración de 75\%. La concentración más alta del extracto condujo a la formación de 100\% plántulas anormales. El extracto de hoja de guayacán no afectó la germinación de semillas varió entre el 97,5 y el 100\%, sin embargo, el potencial alelopático fue visto en características de desarrollo de plántulas de lechuga.
\end{abstract}

Palabras clave: Lactuca sativa L., Plántulas, Semillas.

\section{INTRODUÇÃO}

Kielmeyera coriacea Mart. \& Zucc. (Clusiaceae), conhecida popularmente como pausanto, saco-de-boi, pau-de-são-josé, folha-santa e gordinha, distribui-se amplamente pelo Brasil, desde o estado do Amazonas até São Paulo em áreas de Campo Sujo, Cerrado e Cerradão (SAN0 et al., 2008). A espécie é a mais importante fornecedora de cortiça do Cerrado em função da abundante produção de súber, é melífera, ornamental, além de apresentar atividade farmacológica (MARTINS et al., 2004).

Plantas consideradas medicinais ou aromáticas produzem vários metabólitos secundários (GOBBO-NET0 e Lopes, 2007) que podem ter propriedades alelopáticas com potencial para serem utilizadas como herbicidas naturais, já que a resistência das plantas invasoras aos herbicidas sintéticos tem levado à busca de novas alternativas, menos agressivas ao meio, como é o caso dos aleloquímicos naturais (MATSUMOT0 et al., 2010).

Diversos autores demonstram a possibilidade de controlar espécies invasoras através de aleloquímicos (GATTI et al., 2007; CENTENAR0 et al., 2009; RIBEIR0 et al., 2009; MATSUM0T0 et al., 2010; OLIVEIRA et al., 2014). Os compostos naturais têm várias vantagens sobre os sintéticos, como maior solubilidade em água, ausência de moléculas halogenadas e menor meia vida (RIBEIR0 et al., 2009). Portanto, os aleloquímicos não causariam efeitos prejudiciais atribuídos aos herbicidas sintéticos. 
Silva et al. (2006) observaram que a espécie K. variabilis inibe a germinação de sementes de alface. Entretanto, Gatti et al. (2007) não verificaram efeito de extratos aquosos de folhas de K. coriacea sobre a porcentagem e velocidade de germinação de sementes de alface e gergelim. Além disso, Oliveira et al. (2012c) utilizaram o extrato seco de folhas de K. coriacea em diferentes tipos de solo e não verificaram efeito sobre a porcentagem e velocidade de germinação de sementes de Tabebuia heptaphylla.

A alface (Lactuca sativa L.) é uma espécie usada nos bioensaios para verificar a atividade alelopática por ter a germinação rápida, 0 crescimento linear insensível às diferenças de pH em ampla faixa de variação e, insensibilidade aos potenciais osmóticos das soluções (Rice, 1984).

Assim, o objetivo neste trabalho foi avaliar o potencial alelopático do extrato de folhas de K. coriacea sobre a germinação e formação de plântulas de alface.

\section{MATERIAL E MÉTODOS}

As folhas de K. coriacea foram excisadas de indivíduos adultos, no município de Chapada dos Guimarães (MT), entre as coordenadas geográficas $15^{\circ} 10^{\prime}$ a $15^{\circ} 30^{\prime}$ latitude Sul e $55^{\circ} 40^{\prime}$ a $56^{\circ} 00$ longitude 0este. Em seguida, o experimento foi realizado no Laboratório de Sementes da Faculdade de Agronomia, Medicina Veterinária e Zootecnia (FAMEVZ) da Universidade Federal de Mato Grosso (UFMT), Cuiabá, Mato Grosso, Brasil.

As folhas foram colocadas durante $5 \mathrm{~min}$ em recipientes contendo $10 \mathrm{~mL}$ de hipoclorito de sódio diluído em $500 \mathrm{~mL}$ de água destilada para que fossem descontaminadas superficialmente; em seguida foram lavadas em água destilada e secas com papel toalha. A seguir, as folhas foram trituradas em liquidificador, na proporção de $50 \mathrm{~g}$ de folhas para 500 $\mathrm{mL}$ de água destilada. 0 extrato foi filtrado em papel filtro e armazenado em frascos de vidro (âmbar), na temperatura de $18 \pm 1^{\circ} \mathrm{C}$, segundo metodologia descrita por Mauli et al. (2009),

Para o bioensaio de germinação, foi usado o delineamento experimental inteiramente casualizado com cinco tratamentos constituídos pelas concentrações do extrato foliar obtidas por diluição em água destilada (0, 25, 50, 75 e 100\%), com quatro repetições de 50 sementes de alface do cultivar Elba, adquiridas no comércio local. Nas diferentes concentrações dos extratos, determinou-se o pH e a condutividade elétrica (CE). A partir dos valores de CE determinou-se o 
Bioensaios em sementes de Lactuca sativa L. com extrato de folhas de Kielmeyera coriacea Mart. \& Zucc.

potencial osmótico (P0) de acordo com a fórmula proposta por Ayers e Westcot (1999): Potencial osmótico, em atmosfera $(\mathrm{atm})=-0,36$ * CE. Os dados em atm foram transformados para MPa.

As sementes de alface foram colocadas em caixas de plástico transparentes tipo gerbox $(11 \times 11 \times 3 \mathrm{~cm})$ sobre duas folhas de papel mata-borrão umedecidas com os extratos, na quantidade de 2,5 vezes a massa seca do papel. As caixas foram tampadas e vedadas com filme de plástico e, mantidas em incubadora do tipo BOD a $20^{\circ} \mathrm{C}$, em fotoperíodo de 12 horas, durante sete dias.

Diariamente, anotou-se 0 número de sementes germinadas para determinação da porcentagem e índice de velocidade de germinação (IVG). 0 critério para avaliar a germinabilidade das sementes baseou-se no conceito de germinação fisiológica citada por Marcos Filho (2015), que aponta como germinadas as sementes com protrusão da raiz primária. A velocidade de germinação foi calculada segundo a fórmula de Maguire (1962).

Sete dias após a aplicação dos tratamentos, as plântulas foram classificadas em normais ou anormais de acordo com as especificações das Regras para Análise de Sementes (BRASIL, 2009). Com esses dados calculou-se a porcentagem de plântulas anormais.

Em seguida as plântulas de alface foram avaliadas quanto ao comprimento da parte aérea: região de transição da raiz até a inserção dos cotilédones e, comprimento da raiz: região de transição da parte aérea até o ápice da maior raiz. A massa fresca foi obtida em balança semianalítica e a massa seca, depois de secagem das plântulas, em estufa a $80{ }^{\circ} \mathrm{C}$ durante $24 \mathrm{~h}$, obtendo-se os valores em gramas (BENICASA, 2003).

0 índice de efeito alelopático sugerido por Williamson e Richardson foi calculado de acordo com a fórmula: $\mathrm{RI}=1-\mathrm{C} / \mathrm{T}(\mathrm{T} \geq \mathrm{C})$ ou $\mathrm{RI}=\mathrm{T} / \mathrm{C}-1(\mathrm{~T}<\mathrm{C})$ onde: $\mathrm{C}=$ velocidade de germinação do controle (0\%) e T = velocidade de germinação do tratamento (GA0 et al., 2009).

As variáveis foram submetidas à análise de variância da regressão e quando significativa foram selecionados os modelos com maior $\mathrm{R}^{2}$.

\section{RESULTADOS E DISCUSSÃ0}

Houve acidificação dos extratos em relação à água pura (0\%), no entanto, os valores de pH permaneceram dentro dos padrões aceitáveis para a germinação e crescimento de plântulas 
em testes alelopáticos (Tabela 1). Mayeux e Scifres (1978) afirmam que efeitos do pH em testes alelopáticos são ocasionados por pH abaixo de 3 e acima de 1l. Quanto ao potencial osmótico, os valores foram maiores que -0,2 MPa não sendo, portanto, o fator responsável por possíveis alterações no comportamento germinativo das sementes de alface, de acordo com Gatti et al. (2004).

Tabela 1 - Potencial hidrogeniônico (pH) e osmótico (P0) de extratos aquosos de folhas de Kielmeyera coriacea

\begin{tabular}{ccc}
\hline CONCENTRAÇ̃̃0 D0 EXTRAT0 (\%) & $\mathrm{pH}$ & P0 (MPA) \\
\hline 0 & 7,6 & $-0,00018237$ \\
25 & 3,43 & $-0,01820061$ \\
50 & 3,56 & $-0,01553799$ \\
75 & 3,55 & $-0,02206687$ \\
100 & 3,44 & $-0,02779331$ \\
\hline
\end{tabular}

Fonte: Própria.

Não houve diferença na porcentagem de germinação das sementes de alface colocadas para germinar em papel mata-borrão umedecido com as diferentes concentrações dos extratos aquosos de folhas de K. coriacea, que variou de 98,5 a $100 \%$. No entanto, as demais características foram afetadas pelas concentrações do extrato (Figura 1). Isto confirma o que a maioria dos estudos tem observado (MARASCHIN-SILVA e ÁQUILA, 2006; Carmo et al., 2007; Murakami et al., 2009; Gusman et al., 2011), ou seja, os efeitos alelopáticos não ocorrem sobre a germinação no sentido fisiológico, mas, no desenvolvimento das plântulas.

As variações nos valores do índice de velocidade de germinação das sementes de alface (Figura 1A), no comprimento da raiz e da parte aérea (Figuras 1B e 1C) e massa fresca e seca das plântulas (Figuras 1D e 1E) podem ser explicadas por modelos polinomiais de regressão de segundo grau, onde o efeito alelopático negativo dos extratos foi mais evidente até a concentração de $75 \%$ e, na concentração de 100\% houve tendência de diminuir este efeito, mas, ainda os valores se mantiveram abaixo do controle (0\%). Este mesmo comportamento de reduzir o efeito alelopático negativo nas maiores concentrações também foi observado por Silveira et al. (2012b) ao testarem o efeito do extrato aquoso de jurema-preta (Mimosa tenuiflora) na germinação de sementes de alface. 

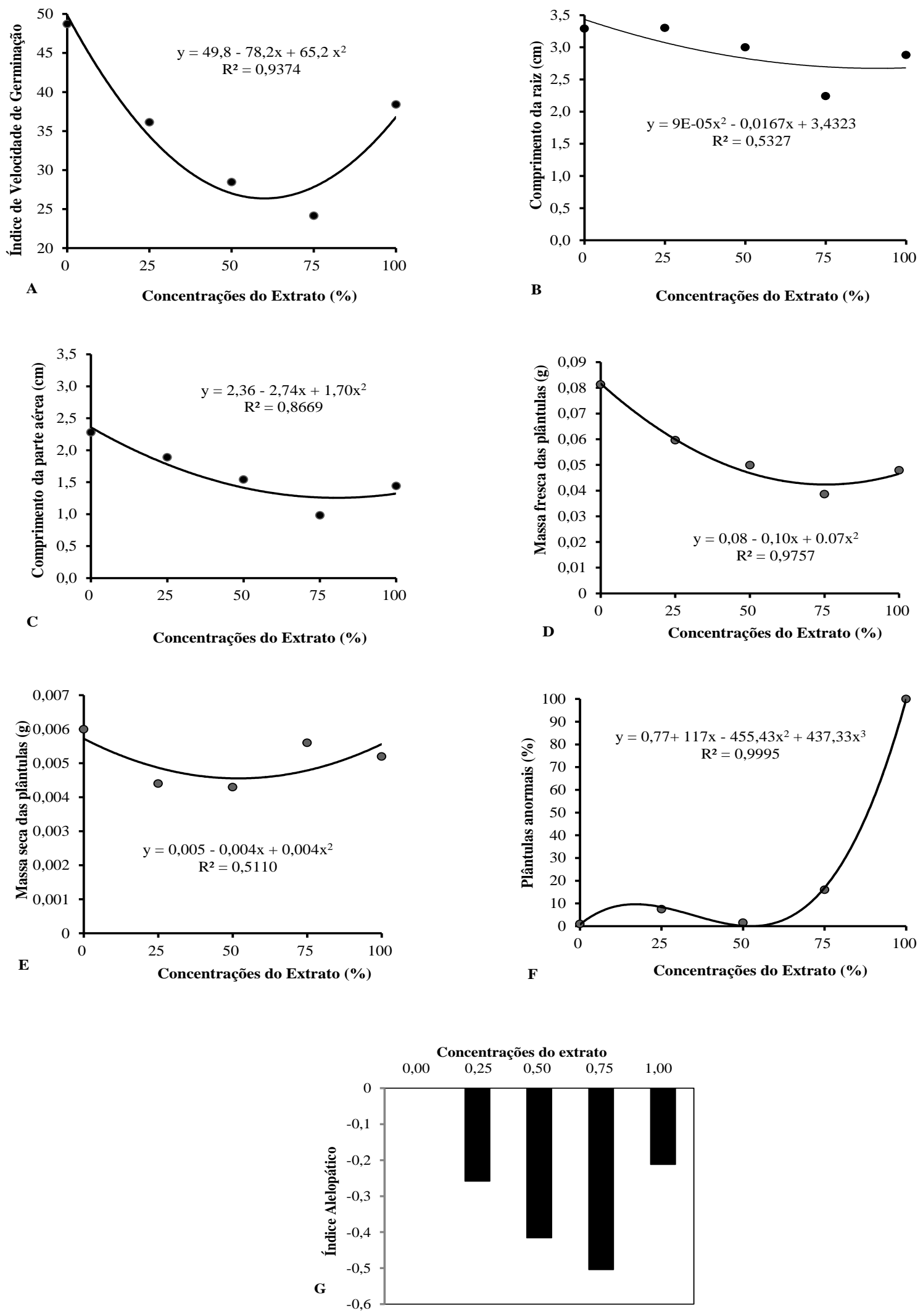

Figura 1. Índice de velocidade de germinação das sementes (A), comprimento da raiz (B), comprimento da parte aérea (C), massa fresca (D) e massa seca das plântulas (E), porcentagem de plântulas anormais (F) e, índice alelopático (G) de plântulas de alface (L. sativa L.) em diferentes concentrações de extrato de Kielmeyera coriacea 
Fonte: Própria.

As variações nos valores do índice de velocidade de germinação das sementes de alface (Figura 1A), no comprimento da raiz e da parte aérea (Figuras 1B e 1C) e massa fresca e seca das plântulas (Figuras 1D e 1E) podem ser explicadas por modelos polinomiais de regressão de segundo grau, onde o efeito alelopático negativo dos extratos foi mais evidente até a concentração de $75 \%$ e, na concentração de 100\% houve tendência de diminuir este efeito, mas, ainda os valores se mantiveram abaixo do controle (0\%). Este mesmo comportamento de reduzir o efeito alelopático negativo nas maiores concentrações também foi observado por Silveira $e t$ al. (2012b) ao testarem o efeito do extrato aquoso de jurema-preta (Mimosa tenuiflora) na germinação de sementes de alface.

Resultados semelhantes a estes, obtidos através do cálculo do índice de velocidade de germinação das sementes, foram encontrados por outros autores. Candido et al. (2010), avaliaram o potencial alelopático de Senna occidentalis L. e observaram significativa redução do índice de velocidade de germinação (IVG) de sementes de alface e tomate quando se aumentou a concentração do extrato. Tur et al. (2010) verificaram redução significativa do IVG de sementes de alface com o aumento da concentração dos extratos de folhas frescas e secas de pingo-de-ouro (Duranta repens L.). Borella et al. (2011) testaram o efeito alelopático de ervamoura (Solanum americanum Mill.) sobre a germinação de sementes de rabanete (Raphanus sativus L.) e verificaram que os extratos aquosos de erva-moura reduziram o número médio de sementes germinadas por dia. A redução do índice de velocidade de germinação evidencia redução da expressão do vigor das sementes, devido ao efeito tóxico dos extratos.

Quanto ao comprimento da raiz (Figura 1B) e a massa seca das plântulas (Figura 1E) o R ${ }^{2}$ indica que cerca de 50\% da variação pode ser explicada pelos modelos ajustados, 0,5327 e 0,5110, respectivamente, no entanto, a análise de variância foi significativa, indicando que as maiores concentrações dos extratos diminuíram os valores dessas características. Rickli et al. (2011) verificaram que o extrato de folhas frescas de Azadirachta indica L. inibiu o crescimento da raiz de alface nas concentrações testadas. A diminuição da massa seca pode ser devida à inibição de mecanismos de hidrólise ou à danificação da estrutura celular (HONG et al., 2004). Comiotto et al. (2011) verificaram que extratos aquosos de Schinus terebinthifolius, proporcionaram redução da massa fresca de plântulas de alface com o aumento das concentrações. 
Bioensaios em sementes de Lactuca sativa L. com extrato de folhas de Kielmeyera coriacea Mart. \& Zucc.

A maior concentração do extrato de K. coriacea ocasionou 100\% de plântulas anormais e, a variação na porcentagem de plântulas anormais entre as diferentes concentrações dos extratos foi explicada pelo modelo polinomial de regressão de terceiro grau (Figura 1F).

As diferenças entre os dados encontrados para porcentagem de germinação, que variou de 98,5 a 100\% e, porcentagem de plântulas anormais, 100\% na maior concentração do extrato, se deve ao fato da avaliação da germinação das sementes ter sido baseada no conceito de germinação fisiológica, que considera como germinadas as sementes com protrusão da raiz primária e não na formação de plântulas normais. A formação de plântulas normais é uma etapa seguinte e, de acordo com Ferreira e Borghetti (2004), o efeito alelopático é mais evidente nas características relacionadas ao desenvolvimento do que ao processo de germinação.

As plântulas classificadas como anormais apresentaram ausência de pelos absorventes na raiz, raízes necrosadas, escurecimento e endurecimento do ápice radicular, geotropismo negativo, raízes primárias atrofiadas e defeituosas, raízes curtas e desproporcionais à parte aérea. 0 endurecimento e escurecimento dos ápices radiculares são evidências de alterações morfológicas e anatômicas causadas por fitotoxinas (CRUZ-0RTEGA et al., 1998). A desproporção entre as raízes e a parte aérea das plântulas, segundo Chung et al. (2001) deve-se ao fato de haver maior contato entre as raízes e o extrato (aleloquímicos) do que as demais estruturas das plântulas.

Vários autores observaram estes efeitos em sementes de alface, tais como Oliveira et al. (2012a) com extratos de juazeiro, Oliveira et al. (2012b) com extratos de mulungu, Silveira et al. (2012a) com extratos de cascas de jurema-preta e, De Conti e Franco (2011) com extratos aquosos de Casearia sylvestris.

0 índice de efeito alelopático (RI) indica estímulo quando apresenta valores positivos em relação ao controle e valores negativos indicam inibição e, foi utilizado por Abdelgaleil e Hashinaga (2007) para demonstrar a ação alelopática causada pelos extratos em bioensaios. Nos dados apresentados (Figura 1G) pode-se observar que todas as concentrações testadas dos extratos de K. coriacea inibiram a velocidade de germinação das sementes de alface, entretanto, a inibição foi menor na concentração maior (100\%). Borella et al. (2011) verificaram que extratos de Schinus mole causaram efeitos inibitórios à germinação de sementes de rabanete proporcional à concentração. 
Portanto, o extrato foliar de K. coriacea em diferentes concentrações não afetou a germinação das sementes e o potencial alelopático foi verificado nas características de desenvolvimento das plântulas de alface.

\section{CONCLUSÃ0}

0 extrato de folhas de K. coriacea apresenta potencial alelopático sobre as sementes de alface.

\section{REFERÊNCIAS BIBLIOGRÁFICAS}

ABDELGALEIL, S.A.M., HASHINAGA, F. Allelopathic potential of two sesquiterpene lactones from Magnolia grandiflora L. Biochemical Systematics and Ecology, v. 35, p. 737-742, 2007.

AYERS, R.S., WESTCOT, D.W. 1999. Water quality for agriculture. Roma: FA0, 97p. (FA0. Irrigation and Drainage Peper, 29).

BENINCASA, M.M.P. Análise de crescimento de plantas: noções básicas. Jaboticabal: FUNEP, 2003. 42 p.

BORELLA, J. WANDSCHEER, A.C.D., PASTORINI, L.H. Potencial alelopático de extratos aquosos de frutos de Solanum americanum Mill. sobre as sementes de rabanete. Revista Brasileira de Ciências Agrárias, v. 6, p. 309-313, 2011.

BRASIL. Ministério da Agricultura e Reforma Agrária. 2009. Regras para análise de sementes. Brasília: SNAD/CLAV. 395p.

CANDID0, A.C.S., SCHMIDT, V., LAURA, V.A., FACCENDA, 0., HESS, S.C., SIMIONATTO, E., PERES, M.T.L.P. Potencial alelopático da parte aérea de Senna occidentalis (L.) Link (Fabaceae, Caesalpinioideae): bioensaios em laboratório. Revista Acta Botânica Brasílica, v. 24, p. 235-242, 2010.

CARMO, F.M.S., BORGES, E.E.L., TAKAKI, M. Alelopatia de extratos aquosos de canela-sassafrás (Ocotea odorifera (Vell.) Rohwer). Acta Botânica Brasílica, v. 21, p. 697-705, 2007.

CENTENARO, C., CORRÊA, L.G.P., KARAS, M.J., VIRTUOSO, S., DIAS, J.F.G., MIGUEL, O.G., MIGUEL, M.D. Contribuição ao estudo alelopático de Erythrina velutina Willd., Fabaceae. Revista Brasileira de Farmacognosia. Brazilian Journal of Pharmacognosy, v. 19 (1B), p. 304-308, 2009.

CHUNG, I.M., AHN, J.K., YOON, S.J. Assessment of allelopathic potential of barnyard grass (Echinochloa crus-gall) on rice (Oriza sativa L.) cultivars. Crop Protection, v. 20, p. 921-928, 2001.

COMIOTTO, A., MORAES, D.M., LOPES, N.F. Potencial alelopático de extratos aquosos de aroeira sobre germinação e crescimento de plântulas de alface. Scientia Agraria Paranaensis, v.10, p. 23-31, 2011.

CRUZ-0RTEGA, R., ANAYA, A.L., HERNÁNDEZ-BAUTISTA, B.E., LAGUNA-HERNÁNDEZ, G. Effects of allelochemical stress produced by Sicyios deppei on seedling root ultrastructure of Phaseolus vulgaris e Curcubita ficifolia. Journal of Chemical Ecology, v. 24, p. 2039-2057, 1998.

DE CONTI, D., FRANC0, E.T.H. Efeito alelopático de extratos aquosos de Casearia sylvestris SW. na germinação e no crescimento de Lactuca sativa L. Revista Brasileira de Agrociência, v. 17, p.193-203, 2011.

FERREIRA, A. G.; BORGHETTI, F. Germinação: do básico ao aplicado. Porto Alegre: Ed. Artimed. 2004. 323p. 
Bioensaios em sementes de Lactuca sativa L. com extrato de folhas de Kielmeyera coriacea Mart. \& Zucc.

GA0, X., LI, M., GA0, Z., LI, C., SUN, Z. Allelopathic effects of Hemisteptalyrata on the germination and growth of wheat, sorghum, cucumber, rape, and radish seeds. Weed Biology and Management, v. 9, p. 243-249, 2009.

GATTI, A.B., PEREZ, S.C.J.G.A., LIMA, M.I.S. Atividade alelopática de extratos aquosos de Aristolochia esperanzae 0. Kuntze na germinação e no crescimento de Lactuca sativa L. e Raphanus sativus L. Acta Botânica Brasílica, v. 18 p. 459-472, 2004.

GATTI, A.B., PEREZ, S.C.J.G.A., FERREIRA, A.G. Avaliação da atividade alelopática de extratos aquosos de folhas de espécies de Cerrado. Revista Brasileira de Biociências, v. 5, p. 174-176, 2007.

G0BBO-NET0, L., LOPES, N.P. Plantas medicinais: fatores de influência no conteúdo de metabólitos secundários. Química Nova, v. 30, p. 374-381, 2007.

GUSMAN, G.S., YAMAGUSHI, M.Q., VESTENA, S. Potencial alelopático de extratos aquosos de Bidens pilosa L., Cyperus rotundus L. e Euphorbia hterophylla L. Iheringia, Série Botânica, v. 66, p. 87-98, 2011.

HONG, N.H., XUAN, T.D., EIJI, T., KHANH, T.D. Paddy weed control by higher plants from Southeast Asia. Crop Protection, v. 23 p. 255-261, 2004.

MAGUIRE, J.A. Speed of germination: aid in selection and evaluation for seedling emergence and vigor. Crop Science, v. 2 , p. $176-177,1962$.

MARASCHIN-SILVA, F., ÁQUILA, M.E.A. Potencial alelopático de espécies nativas na germinação e crescimento inicial de Lactuca sativa L. (Asteraceae). Acta Botânica Brasílica, v. 20, p. 61-69, 2006.

MARCOS FILH0, J. 2015. Fisiologia de sementes de plantas cultivadas. 2.ed. Londrina: ABRATES. 660p.

MARTINS, J.V.C., OTOBONE, F.J., SELA, V.R., OBICI, S., TROMBELLI, M.A., CORTEZ, D. A.G., AUDI, E.A. Activity of hydroethanolic extract from Kielmeyera coriacea stems on central nervous system in rats. Acta Scientiarum Health Sciences, v. 26, p. 365-368, 2004.

MATSUMOTO, R.S., RIBEIR0, J.P.N., TAKA0, L.K., LIMA, M.I.S. Potencial alelopático do estrato foliar de Annona glaba L. (Annonaceae). Acta Botânica Brasílica, v. 24, p. 631-635, 2010.

MAULI, M.M.; FORTES, A.M.T.; ROSA, D.M.; PICCOL0, G.; MARQUES, D.S.; MALAGUTTI, J.C.; LESZCZYNSKI, R. Alelopatia de Leucena sobre soja e plantas invasoras. Semina: Ciências Agrárias, v. 30, n. 1, p. 55-62, 2009.

MAYEUX, H.S., SCIFRES, C.J. Germination of goldenweed seed. Journal of Range Management, v. 31, p. 371-374, 1978.

MURAKAMI, C., CARDOSO, F.L., MAYWORM, M.A.S. Potencial fitotóxico de extratos foliares de Aloe arborescens Miller (Asphodelaceae) produzidos em diferentes épocas do ano. Acta Botânica Brasílica, v. 23, p. 111-117, 2009.

OLIVEIRA, S.C.C., FERREIRA, A.G., BORGHETTI, F. Efeito alelopático de folhas de Solanum lycocarpum A. St.-Hil. (Solanaceae) na germinação e crescimento de Sesamum indicum L. (Pedaliaceae) sob diferentes temperaturas. Acta Botânica Brasílica, v. 18, p. 401-406, 2004.

OLIVEIRA, A.K., COELHO, M.F.B., MAIA, S.S.S., DIÓGENES, F.E.P., MEDEIROS FILHO, S. Atividade alelopática de extratos de diferentes partes de juazeiro (Ziziphus joazeiro Mart. - Rhamnaceae). Acta Botânica Brasílica, v. 26, p. 692-698, 2012a.

OLIVEIRA, A.K., COELHO, M.F.B., MAIA, S.S.S., DIÓGENES, F.E.P., MEDEIROS FILHO, S. Alelopatia de extratos de diferentes órgãos de mulungu na germinação de alface. Horticultura Brasileira, v. 30, p. 478-481, 2012b.

OLIVEIRA, C.C.O., GUALTIERI, S.C.J., DOMINGUEZ, F.A.M., MOLINILLO, J.M.G., MONTOYA, R.V. Estudos fitoquímicos de folhas de Solanum lycocarpum A. St.-Hil (Solanaceae) e sua aplicação na alelopatia. Acta Botânica Brasilica, v. 26, p. $607-618,2012 \mathrm{c}$. 
OLIVEIRA, A.K.M., PEREIRA, K.C.L., MULLER, J.A.I., MATIAS, R. Análise fitoquímica e potencial alelopático das cascas de Pouteria ramiflora na germinação de alface. Horticultura Brasileira, v. 32, p. 41-47, 2014.

RIBEIR0, J.P.N., MATSUMOTO, R.S., TAKA0 L.K., VOLTARELLI, V.M., LIMA, M.I.S. Efeitos alelopáticos de extratos aquosos de Crinum americanum L. Revista Brasileira de Botânica, v. 32, p.183-188, 2009.

RICE, E.L. 1984. Allelopathy. 2ed. New York: Academic Press. 422p.

RICKLI, H.C., FORTES, A.M.T., SILVA, P.S.S., PILATTI, D.M., HUTT, D.R. Allelopathic effect of aqueous extract of Azadirachta indica A. Juss. on lettuce, soybeans, maize, beans and Bidens pilosa. Semina: Ciências Agrárias, v. 32, p. 473-484, 2011.

SANO, S.M., ALMEIDA, S.P., RIBEIR0, J.F. 2008. Cerrado: ecologia e flora. led. Brasília: Embrapa Informação Tecnológica. 1.279p.

SILVA, G.B. DA, MARTIM, L., SILVA, C.L. DA, YOUNG, M.C.M., LADEIRA A.M. Potencial alelopático de espécies arbóreas nativas do Cerrado. Hoehnea, v. 33, p. 331-338, 2006.

SILVEIRA, P.F., MAIA, S.S.S., COELHO, M.F.B. Potencial alelopático do extrato aquoso de cascas de jurema preta no desenvolvimento inicial de alface. Revista Caatinga, v. 25, p. 20-27, 2012 a.

SILVEIRA, P.F., MAIA, S.S.S., COELHO, M.F.B. Potencial alelopático do extrato aquoso de folhas de Mimosa tenuiflora (Willd.) Poir. na germinação de Lactuca sativa L.. Bioscience Journal, v. 28, n. 3, p. 472-477, 2012 b.

TUR, C.M., BORELLA, J., PASTORINI, L.H. Alelopatia de extratos aquosos de Duranta repens sobre a germinação e crescimento inicial de Lactuca sativa e Lycopersicum esculentum. Revista Biotemas, v. 2, p. 13-22, 2010. 